Dossiê - Para além do “ativismo judicial” e da “Judicialização da política” DOI: $10.5433 / 2176-6665.2016 \mathrm{v} 21 \mathrm{~N} 1 \mathrm{P} 264$

\title{
A JUdicialização da POLítica COMO FERRAMENTA dos PARTIDOS GOVERNISTAS (1995-2010)
}

\author{
RAÍSSA JEANINE NothaFT ${ }^{1}$
}

\begin{abstract}
Resumo
A judicialização da política no Brasil tem sido protagonizada por partidos políticos e associações. Para compreender a judicialização como ferramenta dos partidos, diversos estudos se centraram nos partidos de oposição, negligenciando-se os governistas, que também figuram entre postulantes de ações. Busca-se, desse modo, compreender e comparar os casos em que é utilizada pelos partidos da coalizão dos governos de Fernando Henrique Cardoso (1995-1998/1999-2002) e Luiz Inácio Lula da Silva (2003-2006/2007-2010). O estudo foca a contestação de normas federais por meio do principal instrumento de controle concentrado, a Ação Direta de Inconstitucionalidade - ADIN. A análise dos dados encontrados é feita à luz das abordagens teóricas sobre judicialização e da teorização já feita em relação à judicialização pela oposição. Percebe-se, qualitativamente, um uso comum da judicialização dos partidos governistas em ambos os governos, e, quantitativamente, dois usos distintos.
\end{abstract}

Palavras-chave: Judicialização da política. Partidos governistas. Supremo Tribunal Federal. Ações declaratórias de Inconstitucionalidade (ADIs).

\section{JUdicializATION OF POLITICS AS A COALITION PARTIES' TOOL (1995-2010)}

\begin{abstract}
The judicialization in Brazil has been carried out by political parties and associations. To understand the judicialization as party tool, several studies have focused on opposition parties, and little attention has been given to ruling parties. This article analyzes and compares Fernando Henrique Cardoso (1995-1998/1999-2002) and

1 Doutoranda em Ciências Humanas na Universidade Federal de Santa Catarina (UFSC),

Brasil. raissajnothaft@gmail.com


Luiz Inácio Lula da Silva (2003-2006/2007-2010) administrations to understand the uses of judicialization of politics by Coalition parties. The study focuses on Supreme Court challenging Federal acts on grounds of unconstitutionality. The analysis are based on judicialization theoretical approaches and studies about political parties out of power in Brasil. As results, we realize, qualitatively, a common use in both governments, and quantitatively, two distinct uses.

Key-words: Judicialization of politics. Ruling parties. Supreme Court. Declaratory actions of unconstitutionality.

Judicialização da Política no Brasil é fenômeno recentemente
estudado pela Ciência Política. Apesar de estudos sobre o papel político do Judiciário, essa disciplina demorou a incorporá-lo à análise da tomada de decisões governamentais com a mesma profundidade com que consideram o sistema partidário, o Legislativo e o Executivo (TAYLOR; DA ROS, 2008).

Dentre os estudos empíricos já realizados (CARVALHO, 2009; VIANNA; BURGOS; SALLES, 2007; TAYLOR; DA ROS, 2008) foi constatado o protagonismo dos partidos no acionamento dos Tribunais Superiores, dentre eles o Supremo Tribunal Federal (STF), objeto desse trabalho. Contudo, os estudos sobre a judicialização da política pelos partidos têm se focado nos partidos de oposição, e pouca atenção tem se dado aos governistas, que também figuram entre os postulantes de ações. Busca-se, desse modo, compreender em que casos os partidos governistas acessam o judiciário para tomada de decisões políticas. Para isso, faremos a comparação dos padrões de judicialização verificados durante os dois mandatos do presidente Fernando Henrique Cardoso (1995-1998/1999-2002) e compará-los com os dois mandatos do presidente Luiz Inácio Lula da Silva (20032006/2007-2010). Partiremos da análise já iniciada por Taylor e Da Ros (2008), e da bibliografia especializada no tema. Utilizaremos os padrões de coalizões dos respectivos governos desenvolvidos pelos autores Avelar e Cintra (2007) e Pasquarelli (2011), construídas a partir da formação dos Ministérios. 
A classificação dos dados se dará com base nos critérios estabelecidos por Carvalho (2009), por serem mais detalhados e conceituais. Assim como o autor, traremos apenas dados relacionados às Ações Declaratórias de Inconstitucionalidade (ADIs) de legislação federal, analisando, desse modo, apenas a esfera federal e os atores políticos nela envolvidos.

A ideia central é compreender melhor, tendo por base a teorização já feita em relação à judicialização pela oposição, em que casos é utilizada por partidos da coalizão de governo, ou seja, partidos governistas. Os dados utilizados foram extraídos do site do Supremo Tribunal Federal, referentes ao período 1995-2010. O propósito da comparação é, inicialmente, verificar se ocorreram mudanças ao longo do tempo e dos diferentes governos no acionamento do mais alto tribunal do país para contestação de normas federais por meio do principal instrumento de controle concentrado, a Ação Direta de Inconstitucionalidade - ADIN. Em um segundo momento, passamos à identificação de possíveis explicações para as variações - e também para as semelhanças - eventualmente encontradas no levantamento realizado. Em vista disso, este artigo tem início expondo algumas abordagens teóricas sobre a judicialização, aprofundando os estudos sobre o uso da judicialização pelos partidos para, em seguida, ser realizada a análise descritiva dos dados encontrados.

\section{Abordagens Teóricas Sobre Judicialização}

Os estudos sobre as relações das instituições judiciais com as instituições políticas assumiram o nome de judicialização da política. Maciel e Koerner2 (2002) imputam ao projeto de Tate e Vallinder

2 Os autores apresentam diversos sentidos que a expressão é empregada no Brasil e críticas a esses usos, centrando-se no comentário das obras Ministério Público e política no Brasil, 
(1995) a influência inicial da utilização do termo na Ciência Política brasileira. Esses autores definem judicialização da política como ampliação dos campos de atuação dos tribunais via revisão judicial a partir da constitucionalização de direitos e mecanismos de check and balances -, e, também, como a incorporação de procedimentos judiciais no Executivo e no Legislativo.

Vianna et al. (1999), em um dos primeiros textos da Ciência Política brasileira sobre o tema, se utilizou da expressão para descrever as transformações constitucionais pós-1988, as quais permitiram o maior protagonismo dos tribunais a partir da ampliação dos instrumentos de proteção judicial. De acordo com Vianna, Burgos e Salles (2007, p. 41), essa "nova arquitetura institucional adquire seu contorno mais forte com o exercício do controle da constitucionalidade das leis e do processo eleitoral por parte do judiciário, submetendo o poder soberano às leis que ele mesmo outorgou". A Ação Declaratória de Inconstitucionalidade, além de instrumento de defesa de minorias, aparece como recurso institucional estratégico de governo, instituindo, na prática, o Supremo Tribunal Federal como "um conselho de Estado do tipo prevalecente em países de configuração unitária" (VIANNA; BURGOS; SALLES, 2007, p. 43).

Carvalho (2004), no artigo intitulado "Em Busca da Judicialização da Política no Brasil: apontamentos para uma Nova Abordagem" sintetiza o debate em torno da judicialização da política em duas perspectivas, a normativa - que aborda a supremacia constitucional sobre decisões parlamentares majoritárias, havendo autores favoráveis e contrários; e a analítica - que se preocupa com o ambiente político e institucional, em como definir, medir e avaliar o processo de judicialização da política. Nesse artigo, o autor amplia o que ele chama de "conceito mínimo de judicialização" (CARVALHO, 2004, p. 121), que explica a

de Rogério Bastos Arantes, e A democracia e os três poderes no Brasil, organizado por Luiz Werneck Vianna. Como nos filiaremos aos usos de Taylor e Da Ros (2008) e Carvalho (2009), posteriores a esse artigo, não entraremos nessa discussão teórica. 
judicialização no Brasil por meio do aumento expressivo das ações judiciais, e demonstra que o aumento puro e simples do número de processos não implicou uma intervenção efetiva do Judiciário. Por meio de dados como a taxa de julgamento do mérito das ADIs, e a taxa de processos aguardando julgamento, sustenta que o Supremo Tribunal Federal não tem protagonizado um processo de interferência sem precedentes na história brasileira. Em estudo posterior, passa a ver a questão sob diferente ângulo, entendendo judicialização como

[...] um fenómeno que potencia a participação dos membros do poder judiciário no policy-making. Distinguimos então o carácter potenciador, que é caracterizado pelos aspectos formais ou procedimentais, do seu carácter substantivo, que é a intenção dos operadores da lei em participarem no policy-making. Na nossa leitura, a dimensão substantiva ocupa-se de outro fenómeno, o activismo judicial (CARVALHO, 2009, p. 316).

Tendo por base as discussões sobre judicialização da política, partimos de um viés analítico, e da conceitualização de Carvalho (2009) para pensar os padrões de contestação judicial protagonizados por partidos governistas, conforme as abordagens que serão aprofundadas no próximo capítulo.

\section{Judicialização como Ferramenta dos Partidos}

Pesquisas como de Carvalho (2004) demonstram que o aumento puro e simples do número de processos judiciais não implicou uma efetiva intervenção do judiciário. Contudo, a não intervenção não explica o fenômeno que potencializa a participação dos membros do poder judiciário no policy-making. Dessa forma, para o estudo da judicialização como ferramenta dos partidos é necessário levar em conta o uso do judiciário independentemente da expectativa de vitória judicial. Vitória judicial, aqui, significa a revisão judicial com decisão de mérito efetiva. Segundo Carvalho (2009), a taxa de sucesso dos 
partidos é extremamente baixa, apenas 0,8\% da ADIS impetradas por partidos políticos no período 1988-2002 tiveram resultado procedente. Considera-se essa informação relevante, pois demonstra que, mesmo as taxas de sucesso em ADIs já impetradas sendo tão baixas, os partidos continuam se utilizando do Judiciário para se contrapor ou questionar as medidas governistas. Parte-se, então, da conceituação que considera o acesso ao judiciário como medidor do processo de judicialização da política, independentemente do pronunciamento do Judiciário sobre a questão. Taylor e Da Ros (2008, p. 827-828) defendem que

[...] encarar a influência política dos tribunais apenas sob a ótica dos casos em que aqueles efetivamente alteram a legislação significa restringir sobremaneira a análise e deixar sem apreciação táticas políticas importantes que envolvem os tribunais mesmo em contextos em que a vitória judicial não é esperada.

Partindo para as abordagens teóricas explicativas, o comportamento dos partidos no processo de Judicialização seguiria o policy-seeking approach, ou seja, a expansão da jurisdição constitucional sobre o policy-making governamental, como resultado da provocação de decisões judiciais daqueles que perderam no processo legislativo sobre a constitucionalidade de políticas aprovadas pela maioria parlamentar (CARVALHO, 2009). A partir dessa construção teórica, os diferentes atores políticos fariam uso dos tribunais para retardar ou impedir completamente a implementação de políticas públicas, ou desmerecê-las, ou ainda, declarar sua oposição a elas. Esses objetivos táticos (retardar, impedir, desmerecer, declarar) podem estar ligados tanto à crença de que uma lei é inconstitucional, como ao puro fundamento estratégico de se mostrar contra determinada decisão política (TAYLOR; DA ROS, 2008). A isso se soma o fato de que o tribunal é a última instância à qual se pode recorrer para tentar derrotar uma lei e o custo de acionamento é baixo, não sendo, dessa 
forma, necessário, como tática partidária, levar em conta a chance de sucesso ao propor uma ADI.

A análise já feita por Taylor e Da Ros (2008) dos usos da judicialização pelos partidos no governo de Fernando Henrique Cardoso e de parte do governo Luís Inácio Lula da Silva ${ }^{3}$ resultou na formulação de três conjuntos de justificativas. O primeiro deles, bastante explorado por outros autores (CARVALHO, 2009; VIANNA; BURGOS; SALLES, 2007), e também considerado mais comum, é a judicialização como tática de oposição. Trata-se de "empregar os tribunais, literalmente, como uma última instância, à qual se pode recorrer para derrotar determinadas políticas, denunciar as práticas do governo e tornar clara a posição contrária de determinados grupos a estas" (TAYLOR; DA ROS, 2008, p. 838). O segundo conjunto, também muito frequente, é a judicialização como arbitragem de interesses em conflito. Não se trata, nesse caso, de se opor ao governo, mas a estatutos legais que modificam procedimentos e atingem diretamente interesses de grupos específicos. Essa judicialização tem como objetivo atacar regras procedimentais que beneficiem um determinado ator ou um conjunto deles (TAYLOR; DA ROS, 2008). Essas duas formas aparecem tanto no governo FHC quanto no governo Lula.

Ainda dentro da análise dos autores, eles ressaltam um terceiro tipo, o qual chamam de judicialização como instrumento de governo. Esse conjunto, que seria quase inexistente no período FHC, começa a se desenvolver no período Lula e se manifesta a partir do acionamento do órgão de cúpula da magistratura tanto "para superar situações de paralisia decisória ou de impasse legislativo (gridlock) que os juízes resolvem favoravelmente ao governo quanto, de forma direta, para que se anulem estatutos legais que os integrantes da administração governista busquem retirar do ordenamento jurídico" (TAYLOR; DA ROS, 2008, p. 842). Os autores ressaltam que esse uso também pode

3 Período de janeiro de 2003 a abril de 2008. 
decorrer, como nos partidos oposicionistas, da busca por declarar oposição a medidas tomadas nas câmaras legislativas (TAYLOR; DA ROS, 2008). Tendo por base esses tipos teóricos, busca-se analisar os padrões dos usos dos partidos governistas durante os períodos já analisados por Taylor (até 2008), e os períodos do governo Lula posteriores a essa análise.

\section{Dados e Metodologia da Pesquisa}

Os dados foram obtidos através da página do Supremo Tribunal Federal ${ }^{4}$, a partir das estatísticas e da pesquisa processual das ADIs apresentadas pelos partidos que compunham a coalizão dos respectivos governos e a participação ou não no governo na época da entrada da ação no Supremo Tribunal Federal.

A metodologia utilizada se baseia nos modelos desenvolvidos por Carvalho (2009) e Taylor e Da Ros (2008), adeptos do método comparativo. Trataremos somente das ADIs de legislação federal e contra órgão/poder da esfera federal, pois, conforme estudos de Vianna, Burgos e Salles (2007) sobre a judicialização no Brasil, os partidos têm como principal alvo as normas federais.

As categorias de análise utilizadas serão: a) Requerente (partido da coalizão); b) Requerido; c) Tipo de lei; d) Tópico da lei; e) Decisão liminar; f) Decisão de mérito. Busca-se saber se os mesmos critérios de explicação utilizados para os partidos de oposição se aplicam aos partidos governistas e se há, devido a diferença ideológica entre os dois governos, diferenças entre os padrões de judicialização.

\section{Requerente (PARTIDo da COAlizão)}

Tabela 1 - Partidos da Coalizão de Governo FHC

4 http://www.stf.jus.br/. 


\begin{tabular}{|c|c|c|}
\hline Partido (PSDB) & $01 / 95-12 / 02$ (2 mandatos) & 0 \\
\hline $\begin{array}{c}\text { Partido do Movimento } \\
\text { Democrático do Brasil } \\
\text { (PMDB) }\end{array}$ & $01 / 95-12 / 02$ (2 mandatos) & 4 \\
\hline $\begin{array}{c}\text { Partido da Frente Liberal } \\
\text { (PFL) }\end{array}$ & $01 / 95-03 / 02$ & 4 \\
\hline $\begin{array}{c}\text { Partido Progressista } \\
\text { Brasileiro (PPB) }\end{array}$ & $04 / 96-12 / 02$ & 0 \\
\hline $\begin{array}{c}\text { Partido Trabalhista do Brasil } \\
\text { (PTB) }\end{array}$ & $01 / 95-03 / 99$ & 2 \\
\hline $\begin{array}{c}\text { Partido Popular Socialista } \\
\text { (PPS) }\end{array}$ & $04 / 96-10 / 01$ & 11 \\
\hline Total & & \\
\hline
\end{tabular}

Fonte: Adaptado de Brasil (2014).

Tabela 2 - Partidos da Coalizão de Governo Lula

\begin{tabular}{|c|c|c|}
\hline & Período & Frequência \\
\hline Partido Comunista do Brasil (PC do B) & 01/03 - 12/10 (2 mandatos) & 1 \\
\hline Partido dos Trabalhadores (PT) & 01/03 - 12/10 (2 mandatos) & 1 \\
\hline Partido Socialista Brasileiro (PSB) & 01/03 - 12/10 (2 mandatos) & 2 \\
\hline Partido Trabalhista do Brasil (PTB) & 01/03 - 12/10 (2 mandatos) & 9 \\
\hline $\begin{array}{l}\text { Partido do Movimento Democrático do } \\
\text { Brasil (PMDB) }\end{array}$ & $01 / 04-12 / 10$ & 0 \\
\hline Partido Progressista (PP) & $09 / 05-12 / 10$ & 1 \\
\hline Partido Democrático Trabalhista (PDT) & 01/03 - 01/04 e 04/07 - 12/10 & 6 \\
\hline Partido Republicano Brasileiro (PRB) & 09/05 - 04/06 e 04/07 - 12/10 & 0 \\
\hline Partido Liberal (PL) & $01 / 03-04 / 07$ & 3 \\
\hline Partido Popular Socialista (PPS) & 01/03 - 12/06 (1으 mandato) & 2 \\
\hline Partido Verde (PV) & 01/03 - 12/06 (1으 mandato) & 4 \\
\hline Partido Republicano (PR) & $04 / 07-12 / 10$ & 0 \\
\hline Total & & 29 \\
\hline
\end{tabular}

Fonte: Adaptado de Brasil (2014). 
Entre as ADINs analisadas do governo Lula, constavam no polo passivo da demanda o Congresso Nacional (CN) - 21 casos, o Presidente da República (PR) - 21 casos, o Tribunal Superior Eleitoral (TSE) - 4 casos, a Receita Federal -1 caso e o Banco Central - 1 caso. Muitas vezes mais de um dos requeridos era citado, sendo, na maioria dos casos, a solidariedade passiva composta pelo Presidente da República e o Congresso Nacional. No Governo FHC, temos como requeridos o Presidente da República - 2 casos, o Congresso Nacional - 6 casos, o Tribunal Superior Eleitoral (TSE) - 1 caso e as Mesas da Câmara dos Deputados e do Senado Federal - 1 caso. Os padrões de multiplicidade de requeridos e as porcentagens podem ser observados nos gráficos abaixo:

\section{REQUERIDO}

Gráfico 1 - Governo FHC

\section{Governo FHC}

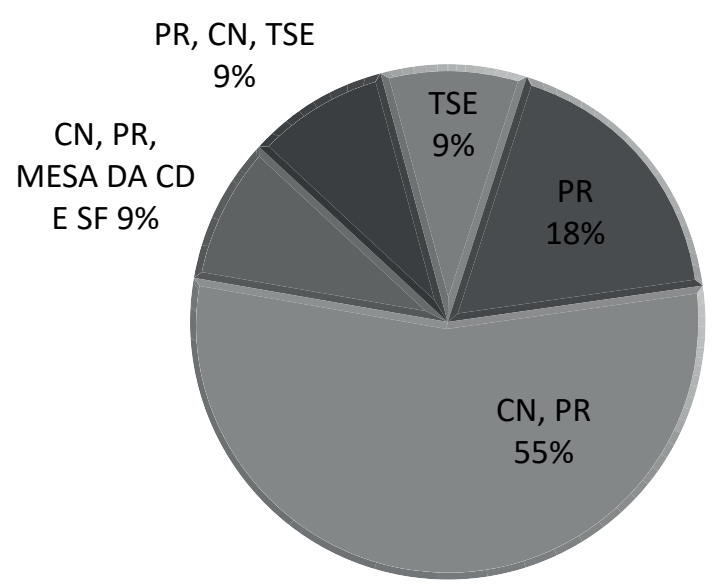

Fonte: Adaptado de Brasil (2014).

Gráfico 2 - Governo Lula 


\section{Governo Lula}

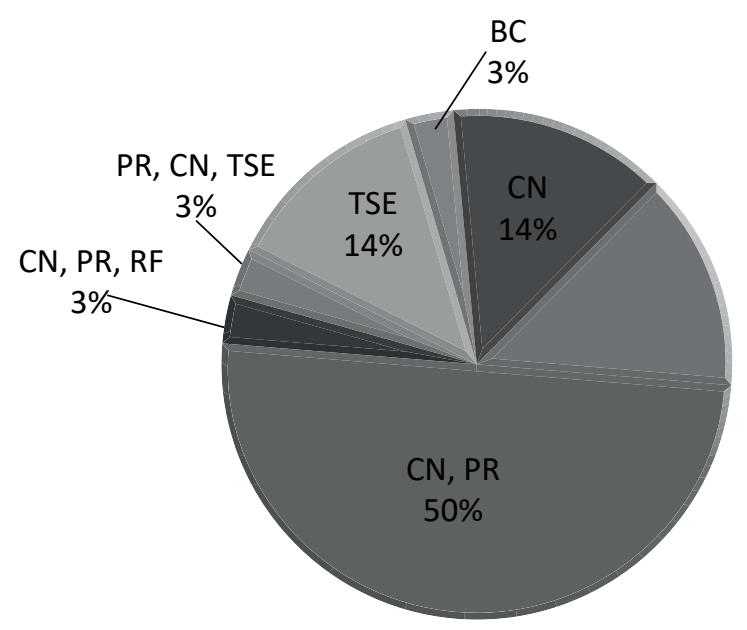

Fonte: Adaptado de Brasil (2014).

\section{TIPO DE LEI}

Um aspecto importante, para entendermos a utilização da judicialização pela coalizão governista, é analisar que tipo de lei e qual os conteúdos que vem sendo questionados no Tribunal Constitucional. Essas se dividem em: Legislação ordinária - todo o texto legal produzido pelos poderes executivo e legislativo que possua função de ordenação, regulação e controlo do quotidiano da administração pública. Portanto decisão administrativa, ato declaratório, resolução, portaria, consolidação das leis do trabalho (CLT), decretos, deliberações, convênios, comissão parlamentar de inquérito (CPI), lei federal, instrução normativa, circular, entre outras (CARVALHO, 2009); Decisão judicial e/ou administrativa: aqui foram classificadas todas as decisões judiciais e atos administrativos do poder judiciário e do Ministério Público e ainda os atos administrativos da Ordem dos Advogados do Brasil (OAB); Medida provisória; Lei complementar; Emenda constitucional. 
Como em uma única ADIN mais de um tipo de lei pode ser contestado, a tabela abaixo demonstra a quantidade de processos em que determinado tipo de lei foi citada.

TABELA 3 - Tipo DE LEI

\begin{tabular}{|c|c|c|}
\cline { 2 - 3 } \multicolumn{1}{c|}{} & FHC & Lula \\
\hline Emenda Constitucional (EC) & 1 & 4 \\
\hline Lei Complementar (LC) & 2 & 3 \\
\hline Legislação Ordinária (LO) & 6 & 16 \\
\hline Medida Provisória (MP) & 2 & 5 \\
\hline Decisão judicial e/ou administrativa (DJA) & 1 & 3 \\
\hline
\end{tabular}

Fonte: Adaptado de Brasil (2014).

O controle das Medidas Provisórias, que é manifestação bastante frequente do uso da via judicial pelos partidos de oposição, por seu caráter mais imediato de mudança e por muitas vezes alterar políticas de elevada repercussão, aqui aparece em 7 casos. Entre eles, temos quatro casos em que a manifestação do partido seguiu a linha de contestação oposicionista, já os demais levantaram questões pontuais consideradas polêmicas, e, em um caso, tivemos contestação de norma sancionada no governo anterior. Dessa forma podemos notar um maior controle dos partidos governistas sobre a legislação ordinária, demonstrando maior contestação dos temas explorados pelo Congresso.

\section{TópICO DA LeI}

Gráfico 3 - Assuntos Contestados em CAda governo 


\section{Assuntos contestados em cada governo}

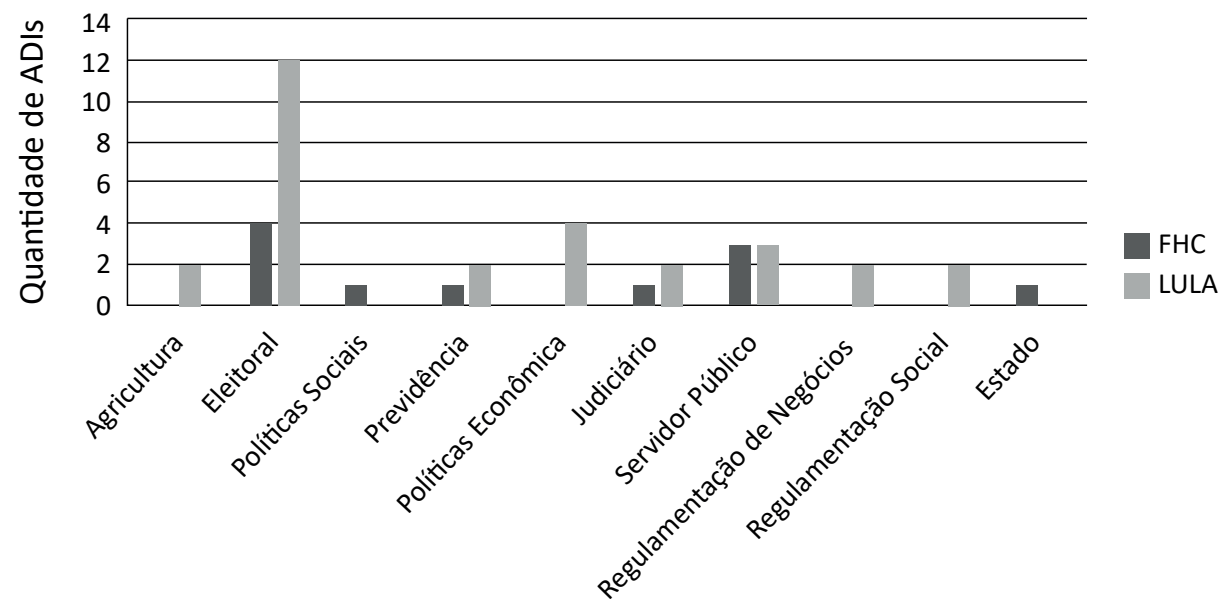

Fonte: Adaptado de Brasil (2014).

O tema mais debatido em ambos governos foi o relativo a legislações eleitorais. No governo FHC, as legislações contestadas foram a Resolução 19512/96 TSE, a Lei 9096/95, a Lei Complementar 64/90 e as súmulas 8 e 12 do TSE, a Lei 9504/97 e a Resolução 20106/98 TSE. A primeira delas foi proposta pelo PPB em relação ao previsto na Resolução 19512/96 TSE sobre a participação de autoridades públicas na propaganda eleitoral, tendo sido julgada prejudicada. Em seguida, o PFL contestou a necessidade de comunicação ao partido e ao juiz da zona eleitoral para cancelar filiação, quando da filiação a outro partido, afirmada pelo art. 22, §único da Lei 9096/95. O Tribunal julgou a demanda improcedente. O PMDB questionou os casos de inelegibilidade previstos na Lei Complementar 64/90 e nas súmulas 8 e 12 do TSE, tendo a ação sido extinta por falta de procuração, ou seja, por questões meramente formais. Por fim, o PPS questionou as normas relativas aos horários da propaganda obrigatória gratuita, previstas na Lei 9504/97 e na Resolução 20106/98 TSE. O Supremo não conheceu da ação. 
No governo Lula, a única ação proposta pelo PT se relacionou com temas eleitorais e de direito políticos, no qual o partido questiona a necessidade de apresentação concomitante da identidade e do título de eleitor para votar, instituída pela Lei 9504/97, ou seja, no governo FHC.

O segundo tema mais abordado, no governo Lula, foi Política Econômica, o qual não apresentou nenhuma demanda no governo FHC. Em dois dos quatro casos, a legislação questionada era do período FHC. Em seguida, temos as legislações sobre os Servidores Públicos, que tiveram igual quantidade de demandas. No governo FHC foram contestadas a Lei 9528/97, que versa sobre a aposentadoria dos magistrados classistas temporários da justiça do trabalho; a Lei 8935/94 em relação à impossibilidade de cumulação da atividade notarial com o cargo de Vereador, a qual foi deferida em parte liminarmente; e o art. 201 da LC 75/93 que restringia a concorrência à promoção nas carreiras do Ministério Público. Já no governo Lula, os estatutos contestados foram a Lei 8625/93 e LC 75/93 que versam sobre as atribuições do Ministério Público, pelo PL; a EC 19/98 e a EC 41/03 sobre diversas questões concernentes a Administração Pública, pelo PDT; e o Art. $1^{\circ}$ da EC 41/03, sobre o teto do funcionalismo público, pelo PTB.

Cabe ressaltar que, no governo FHC, dois estatutos legais foram questionados por partidos governistas e opositores conjuntamente. O primeiro deles foi a EC 14/96 e a Lei no 9424/96 que instituem o Fundo de Manutenção e desenvolvimento do ensino fundamental e de valorização do magistério. Foi alegada pelo PMDB, juntamente com PT, PV, PC do B e PDT, ofensa ao princípio federativo pela atribuição da nova função à união da garantia de equalização de oportunidades educacionais, ferindo a autonomia estatal. O segundo caso é relacionado às normas de fornecimento de energia elétrica 
instituídas com a MP 2148-1/01, proposta pelo PPS, juntamente com o PT, o PC do B, o PDT e o PSB.

As ações no tema Agricultura, impetradas pelo PV, referentes às medidas provisórias de 2003 e 2004, que estabeleceram as normas sobre o plantio e a comercialização da soja geneticamente modificada das safras de 2004 e 2005, respectivamente, demonstram o típico caso do partido defendendo bandeiras internas, demonstrando sua não aprovação à medida específica tomada pelo governo.

\section{Decisão Liminar e de Mérito}

Das 11 ADIs dos mandatos FHC, apenas uma liminar teve deferimento em parte, sendo todas as outras indeferidas ou prejudicadas. Entre as decisões de mérito não houve procedência de pedidos, e duas ações aguardam julgamento, entre elas aquela que teve o deferimento da liminar. A maioria das ADIs do governo Lula aguardam julgamento tanto em sede liminar como no mérito. Em sede liminar, entre as já analisadas, há uma tendência a não manifestação, sendo a maioria prejudicada.

TABELA 4

\begin{tabular}{|c|c|c|c|}
\cline { 3 - 4 } & \multicolumn{1}{|c|}{ Liminar } & Mérito & \multicolumn{1}{c|}{12} \\
\hline Aguardando Julgamento & 10 & Aguardando julgamento & 4 \\
\hline Deferida & 2 & Improcedente & 4 \\
\hline Deferida em parte & 1 & Não conhecido & 1 \\
\hline Negado de segmento & 1 & Negado seguimento & 5 \\
\hline Prejudicada & 14 & Prejudicada & 2 \\
\hline
\end{tabular}

Se compararmos entre os governos o grau de sucesso das ADIs apresentadas pelos partidos governistas teremos, em sede liminar, 
taxa semelhante $(9 \% \text { e } 10 \% \text {, respectivamente })^{5}$. Já no mérito, as ações do governo FHC ainda6 não apresentaram manifestação procedente, enquanto que $6 \%$ das ações do governo Lula tiveram pronunciamento favorável em parte. Essa porcentagem dobra se considerarmos somente as ações já julgadas.

\section{Análise de Dados}

No governo FHC, das 234 ADIs propostas por partidos contra normas federais, temos 11 apresentadas por partidos governistas, o que configura 4\%. Enquanto, no Governo Lula, das 134, 29 são propostas por partidos da coalizão de governo, somando $21 \%$ das ADIs. Podemos verificar a partir desses dados, uma diminuição em números absolutos da judicialização pelos partidos, e um aumento tanto proporcional, como em números absolutos, da judicialização pelos partidos governistas.

Gráfico 4 - ADIs de PARTIDOS POR PERÍODOS DE GOVERNO

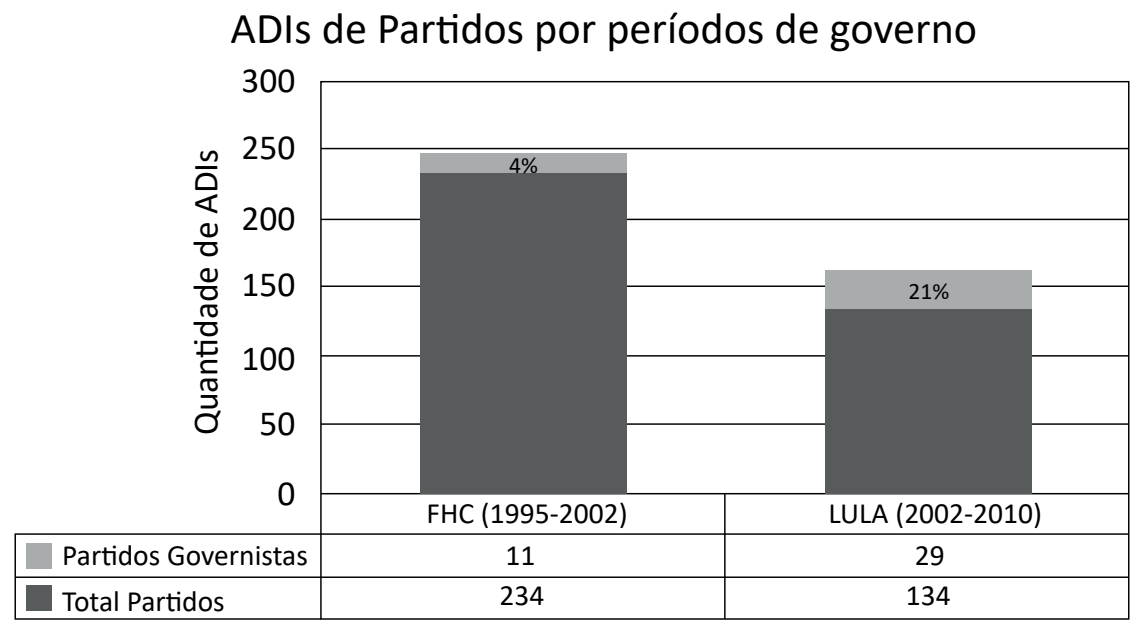

Fonte: Adaptado de Brasil (2014) e Avelar e Cintra (2007).

5 Tendo sido desprezada a informação relativa ao deferimento integral ou em parte.

6 Fala-se "ainda" tendo em vista que duas ações ainda não possuem pronunciamento definitivo. 
A essa diferença quantitativa da judicialização como ferramenta dos partidos entre os dois governos foram levantadas diversas hipóteses. Vianna, Burgos e Salles (2007) explicam essa queda no número total pela ausência de $\mathrm{ADIs}$ do $\mathrm{PT}$, que era até então o principal proponente. Os autores demonstram que 43,5\% das ações promovidas por partidos no governo FHC foram propostas pelo PT, o que em números absolutos significa 102 de 234. Já durante o governo Lula, o PT propôs apenas uma. O PSDB, entretanto, não fez uso, na mesma proporção que o PT, quando na oposição. Conforme os autores, basta

[...] notar que, enquanto no período FHC os partidos de direita propuseram menos de uma Adin por ano, no período Lula nove delas foram propostas. Assim, de uma perspectiva mais geral, a análise das Adins aponta para o fato de elas se afirmarem como uma via complementar de disputa política e de exercício da oposição, mais utilizada pela esquerda, mas igualmente mobilizada pelo centro e pela direita (VIANNA; BURGOS; SALLES, 2007, p. 69).

Ao tentar explicar essa diferença na judicialização nos governos FHC e Lula, Taylor e Da Ros (2008) negam a divisão em partidos de esquerda, centro e direita apresentada por Vianna, Burgos e Salles (2007). Contudo, na verificação dos dados, percebemos uma diminuição no número total de ADIs propostas por partidos de oposição ao mesmo tempo que há um aumento no número de ADIs propostas pelos partidos da coalizão no governo Lula. Consequentemente fica difícil desconsiderar uma possível tendência dos partidos de oposição ao governo de FHC e passam ao governo no mandato de Lula a um maior uso do Judiciário, conforme apontado com Vianna, Burgos e Salles, não sendo necessário, contudo, ligar essa tendência a recortes ideológicos.

Taylor e Ros (2008) vão falar na diferença dos atores em cada momento, no sentido que a estratégia judicial é apenas mais uma 
de inúmeras estratégias que os partidos têm para fazer oposição. Analisando os dados, percebemos que o PDT e o PTB juntos movimentaram mais o judiciário (15 ADIs - 9, PTB e 6, PDT) durante o governo Lula que todos os partidos juntos da coalizão de governo do FHC. O PDT já se mostrava ativo no governo FHC, tendo proposto 35 ações nesse período, enquanto era oposição. Já o PTB fazia parte da coalizão de governo, sendo um dos dois partidos que não acessou o judiciário nesse governo. Levando em conta que o PTB se manifestou sobre diversos temas no governo Lula, isso pode demonstrar um grau de identidade maior do PTB com as políticas do governo do PSDB. Soma-se ainda o fato de a coalizão do Governo Lula ter contado com 12 partidos, o dobro do período FHC, sendo que no governo Lula três partidos não se manifestaram judicialmente. No governo Lula os partidos que não propuseram ações foram o PMDB, o PR e o PRB. No governo FHC, o PMDB foi, junto com o PPB, o partido mais ativo, responsável por 4 das 11 ações.

Partindo para a análise substantiva do uso das ADIs nos dois períodos, podemos perceber semelhanças e diferenças nos comportamentos dos partidos governistas. Aprofundando a análise dos usos da judicialização de Taylor e Da Ros (2008), nota-se que alguns temas exemplificados como típicos do uso da judicialização como ferramenta da oposição aparecem dentro das ações propostas por partidos da base de ambos os governos. No governo FHC temos a ADI 1636 do PPB contra a MP 1523/97, que altera os critérios de diferentes benefícios previdenciários, e no governo Lula temos a ADI 3872 do PTB contra a Emenda Constitucional 41/03, que estabelece a chamada reforma da previdência, e as ADIs contra as MPs 131/03 e 223/04, que regulamentam o plantio e a comercialização de soja geneticamente modificada, do Partido Verde. Casos como esses nos mostram que, quando os interesses dos partidos se confrontam com os interesses do governo, independentemente de fazerem parte ou não 
da coalizão de governo, os interesses partidários tendem a prevalecer. Esse uso acaba se aproximando do que Taylor e Da Ros (2008) vão chamar de judicialização como arbitragem de interesses de conflito. Essa mesma dinâmica transparece nos casos em que o tema de interesse é a legislação eleitoral, tendo em vista que normas do governo podem acabar prejudicando algumas ou várias legendas da base governista nas futuras competições políticas. Aqui se insere a contestação das leis no 9.096, 9.100, 9.504 e 11.300, além da Resolução no 21.702, do TSE, que são leis que redistribuem o tempo de duração do horário eleitoral gratuito em rádio e televisão, instituem regras para o exercício da propaganda partidária, fixam prazos e limites para o registro de candidaturas e estabelecem o número de cargos em disputa.

O terceiro uso, que seria relacionado diretamente como instrumento de governo, e que estaria presente somente no Governo Lula, aparece em poucas ADIs da coalizão governista. Taylor e Da Ros (2008) trabalham com dois exemplos, um deles seria nos casos em que o próprio presidente da República propõe ADIs - as quais não serão analisadas aqui tendo em vista que o objeto desse trabalho é analisar o comportamento dos partidos da coalizão de governo - e o outro seria os casos em que o governo corrente tenta corrigir o que considera um erro político do passado. Nesse segundo caso, cabem cinco ADIs: uma do PC do B que se opõe a trechos da Lei 9491/97, que dispõe sobre o Programa Nacional de Desestatização, sancionada no período FHC, buscando reduzir o leque da política de privatizações; duas de autoria do PV contra a EC 20/98; uma de autoria do PP contra o art. 32 da Lei 9430, que institui limitações ao poder de tributar e uma de autoria do PL contra a legislação que estabelece a competência do Ministério Público. 


\section{Considerações Finais}

De acordo com a análise de Arantes (2004), que define o sistema constitucional brasileiro como liberal de contenção da maioria política por meio de um sistema ultra descentralizado de controle constitucional, seria possível supor que os partidos da coalizão de governo se utilizam da judicialização como forma de trazer à tona questões de minorias que não tivessem aceitação no Congresso. Entretanto, os dados apresentados demonstram que a realidade é bem diversa. O tema mais recorrente é o processo eleitoral, que interfere nos partidos independentemente se congregam a oposição ou o governo. Percebe-se, desse modo, um uso comum da judicialização dos partidos governistas em ambos os governos, o qual se enquadraria na judicialização como arbitragem de interesses em conflito.

Por outro lado, o estudo quantitativo dos dados apresentou ao menos duas diferenças nos usos das ADIs durante os governos FHC e Lula. A primeira delas foi a diminuição do uso do judiciário pelos partidos em termos globais, e a outra foi o aumento no uso pelos partidos da coalizão de governo. Tendo em vista a ausência de mudanças institucionais que pudessem afetar os incentivos a judicialização (TAYLOR; DA ROS, 2008), sem a pretensão de esgotar o assunto, trabalhamos com duas correntes explicativas que se somam.

Primeiramente, a diminuição da judicialização pelos partidos em termos totais pode ser explicada pela mudança dos atores, levando em conta que, o Partido dos Trabalhadores, enquanto partido de oposição, era responsável por quase a metade das ADIs que questionavam leis federais. Já, para explicar o aumento do uso da judicialização pelos partidos governistas durante o governo Lula, acredita-se que intervenham alguns fatores concomitantes. Os dados demonstram que o uso da judicialização como instrumento de governo, singularidade do governo Lula, está presente em apenas cinco das 
vinte e nove ADIs. Desse modo, a essa variável explicativa, deve-se somar o maior número de partidos da coalizão do governo Lula chegando, em momentos, ao dobro do número de partidos da coalizão do governo FHC -, e a possível resistência de um dos partidos da coalizão do governo às políticas implementadas. Essas variáveis somadas explicariam a diferença quantitativa entre o acesso aos tribunais pelas coalizões dos dois governos.

\section{REFERÊNCIAS}

ARANTES, Rogério. Judiciário: entre a justiça e a política. In: AVELAR, Lúcia; CINTRA, Antônio Octávio (Org.). Sistema político brasileiro: uma introdução. São Paulo: Unesp, 2004. p. 79-108.

AVELAR, Lúcia; CINTRA, Antônio O. (Org.). Sistema político brasileiro: uma introdução. São Paulo: Unesp, 2007.

BRASIL. Supremo Tribunal Federal. ADI, ADC, ADO e ADPF. Disponível em: $<\mathrm{http}$ //www.stf.jus.br/portal/peticaoInicial/pesquisarPeticaoInicial.asp $>$. Acesso em: 20 ago. 2014.

CARVALHO, Ernani. Em busca da judicialização da política no Brasil: apontamentos para uma nova abordagem. Revista de Sociologia e Política, Curitiba, v. 23, p. 115-126, 2004.

CARVALHO, Ernani. Judicialização da política no Brasil: controle da constitucionalidade e racionalidade política. Análise Social, Lisboa, v. 44, n. 191, p. 315-335, 2009.

MACIEL, Débora A.; KOERNER, Andrei. Sentidos da judicialização da política: duas análises. Lua Nova, São Paulo, n. 57, p. 114 -133, 2002.

PASQUARELLI, Bruno V. L. Formação de coalizões, apoio legislativo e atuação partidária no presidencialismo brasileiro. In: ENCONTRO ANUAL DA ANPOCS, 35., 2011, Caxambu. Anais... Caxambu, 2011. Disponível em $<$ http://portal.anpocs.org/portal/index.php?option=com_docman\&task=doc_ view\&gid=1114\&Itemid=353>. Acessado em 10 ago. 2014 .

TAYLOR, Matthew M.; DA ROS, Luciano. Os partidos dentro e fora do poder: a judicialização como resultado contingente da estratégia política. DADOS, Rio de Janeiro, v. 51, n. 4, p. 825-864, 2008. 
VIANNA, Luiz Werneck et al. A judicialização da política e das relações sociais no Brasil. Rio de Janeiro: Revan, 1999.

VIANNA, Luiz Werneck; BURGOS, Marcelo B.; SALLES, Paula M. Dezessete anos de judicialização da política. Tempo Social, São Paulo, v. 19, n. 2, p. 39-85, 2007. 